\title{
Retention of aberrant cortisol secretion in a patient with bilateral macronodular adrenal hyperplasia after unilateral adrenalectomy
}

This article was published in the following Dove Medical Press journal:

Therapeutics and Clinical Risk Management

\author{
Sho Tanaka' \\ Midori Fujishiro² \\ Yoshihiro Nakamura' \\ Yoshinari Hatanaka' \\ Masanori Abe' \\ 'Division of Nephrology, \\ Hypertension and Endocrinology, \\ Department of Internal Medicine, \\ Nihon University School of Medicine, \\ Tokyo, Japan; ${ }^{2}$ Division of Diabetes \\ and Metabolic Diseases, Nihon \\ University School of Medicine, \\ Tokyo, Japan
}

Correspondence: Sho Tanaka

Division of Nephrology, Hypertension and Endocrinology, Department of Internal Medicine, Nihon University School of Medicine, 30-I Kamicho,

Oyaguchi, Itabashi-ku, Tokyo

173-8610, Japan

Tel $+813397281 \mathrm{II}$

Fax +813397283 II

Email tanaka.sho@nihon-u.ac.jp

\begin{abstract}
Aberrant cortisol secretion responses after exogenous stimuli such as upright posture, eating a mixed meal or receiving agents influencing aberrant G-protein-coupled receptors in adrenal glands, are often observed in patients with bilateral macronodular adrenal hyperplasia (BMAH). However, little is known about whether this aberrant response is retained after unilateral adrenalectomy. Here, we describe a 61-year-old postmenopausal Japanese woman with unsatisfactorily controlled hypertension who was referred to us for further investigation due to her pre-obesity characteristics (body mass index $28.4 \mathrm{~kg} / \mathrm{m}^{2}$ ). Cushing's signs and serum cortisol at $16.2 \mu \mathrm{g} / \mathrm{dL}$ with undetectable adrenocorticotropic hormone indicated adrenal Cushing's syndrome. Adrenal imaging revealed bilaterally enlarged adrenal glands with 131-I adosterol uptake; hence, BMAH was diagnosed. Preoperatively, in vivo screening for aberrant adrenal receptors revealed an aberrant response of cortisol secretion on metoclopramide challenge. The patient underwent unilateral adrenalectomy; thereafter, glucocorticoid replacement therapy was reduced to hydrocortisone $15 \mathrm{mg}$ /day at postoperative day 6 . Fasting morning serum cortisol level measured at postoperative day 8 was $2.96 \mu \mathrm{g} / \mathrm{dL}$, suggesting adrenal insufficiency. However, following metoclopramide administration serum cortisol level rose to $19.7 \mu \mathrm{g} / \mathrm{dL}$, indicating potential efficient adrenal function. Aberrant cortisol secretory capacity was thus preserved in BMAH, even in a state of adrenal insufficiency after unilateral adrenalectomy. Caution should be exercised when assessing the hypothalamus-pituitary-adrenal axis, because in this patient, a high cortisol level did not guarantee appropriate adrenal function when the patient was challenged by exogenous stimuli.
\end{abstract}

Keywords: adrenal glands, Cushing's syndrome, glucocorticoids, hydrocortisone, metoclopramide, receptors, G-protein-coupled

\section{Introduction}

Bilateral macronodular adrenal hyperplasia (BMAH) is a subtype of adrenal Cushing's syndrome, and is characterized by bilaterally enlarged adrenal glands consisting of nonpigmented macronodules. The molecular mechanisms of cortisol secretion in BMAH, which does not depend on circulating adrenocorticotropic hormone (ACTH) released by the pituitary gland, have become clear in the last two decades. It is widely recognized that cAMP signaling evoked by activation of aberrant G-protein-coupled receptors (GPCRs) in adrenal glands largely contributes to steroid genesis. ${ }^{1}$ Clinically, this is confirmed by aberrant responses of serum cortisol level on challenge by endogenous stimuli such as upright posture, eating a mixed meal or exposure to certain chemicals. ${ }^{1}$ Previous investigations have demonstrated that metoclopramide, an agent frequently used for alleviating gastrointestinal symptoms, stimulates adrenal serotonin type 4 
receptors in some cases of BMAH, leading to excess cortisol in vivo and in vitro. ${ }^{2-8}$ There are several different treatment modalities for patients with BMAH, including unilateral adrenalectomy. ${ }^{9}$ In patients who underwent this operation, assessing residual cortisol secretion capacity is clinically important in order to avoid unnecessary steroid replacement therapy while reducing the risk of adrenal insufficiency or crisis. While more than 20 cases of BMAH with aberrant responses against metoclopramide have been reported in the literature, the impact of metoclopramide on cortisol secretion from the remaining adrenal gland in patients after unilateral adrenalectomy remains unknown. ${ }^{2,3,5,7,8}$ Herein, we report a Japanese woman with BMAH in whom aberrant serum cortisol levels on metoclopramide use were seen despite adrenal insufficiency after surgery.

\section{Case description}

A 61-year-old postmenopausal Japanese woman was referred to us for further investigation of her pre-obese state. She had had hypertension, dyslipidemia and osteoporosis for 10 years. Hypertension was treated with telmisartan $80 \mathrm{mg} /$ day, and amlodipine $7.5 \mathrm{mg}$ /day but was not satisfactorily controlled. Home-monitored blood pressure level remained 130-160/70$90 \mathrm{mmHg}$. Her family history included hypertension in an elderly sister but was otherwise unremarkable. The patient habitually smoked a pack of cigarettes per day and consumed $30 \mathrm{~g}$ alcohol daily.

On physical examination, pre-obesity was observed: height $147 \mathrm{~cm}$, weight $61.3 \mathrm{~kg}$ and BMI $28.4 \mathrm{~kg} / \mathrm{m}^{2}$. Additionally, centripetal obesity, facial plethora, skin atrophy with easy bruising, proximal lower limb weakness and mild moon face were apparent. Randomly measured serum cortisol at $16.2 \mu \mathrm{g} / \mathrm{dL}$ (reference range, 6.24-18.0) with undetectable ACTH at $<2 \mathrm{pg} / \mathrm{mL}$ (reference range, 7.2-63.3) indicated adrenal Cushing's syndrome. Computed tomography and single photon emission computed tomography using 131-I adosterol revealed bilateral nodules in the adrenal glands. Maximum nodule size in the left-side gland was $34 \mathrm{~mm}$ with strong uptake, and $31 \mathrm{~mm}$ with relatively weak uptake in the right-side gland (Figure 1). Circadian variation of serum cortisol and ACTH levels was abnormal; Cortisol levels were $11.2,11.4,14.5$ and $10.8 \mu \mathrm{g} / \mathrm{dL}$ at $0.00 \mathrm{am}, 6.00 \mathrm{am}, 0.00 \mathrm{pm}$ and $6.00 \mathrm{pm}$, respectively, and $\mathrm{ACTH}$ was undetectable throughout the day. Urinary free cortisol excretion was high at $380 \mu \mathrm{g} /$ day (reference range, 11.2-80.3). Reduction of serum cortisol level was not seen in overnight dexamethasone suppression tests; morning serum cortisol levels following 1 or $8 \mathrm{mg}$ dexamethasone administration were 11.3 and $15.3 \mu \mathrm{g} /$
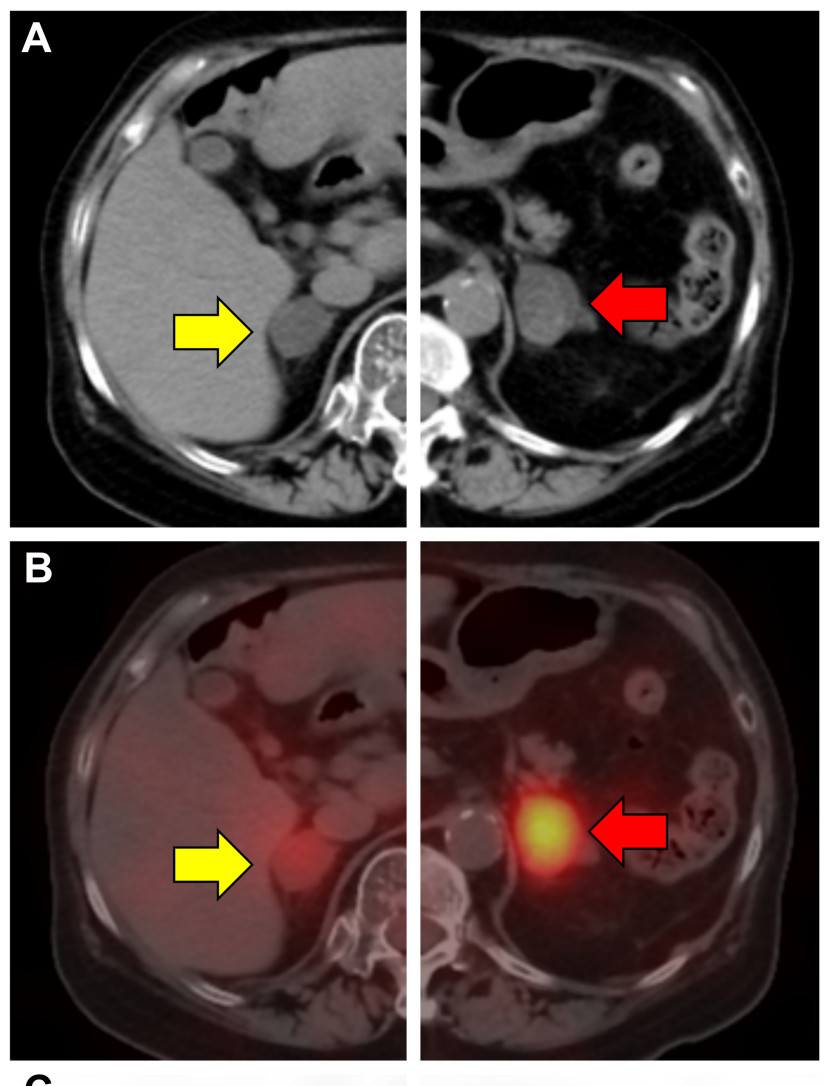

C

Figure I Imaging of adrenal glands.

Notes: The arrows indicate the nodule in the right (yellow) and left (red) adrenal gland. (A) Image of CT. (B) Merged image of CT and I3I-I adosterol SPECT. (C) Image of I3I-I adosterol SPECT.

Abbreviations: CT, computed tomography; SPECT, single photon emission computed tomography.

$\mathrm{dL}$, respectively. Responses of serum cortisol after eating a mixed meal, on intravenously administered glucagon $1 \mathrm{mg}$, or orally administered metoclopramide $10 \mathrm{mg}$ were investigated. Additionally, responses against ACTH and gonadotropinreleasing hormone (GnRH) were assessed using intravenous synacthen $250 \mu \mathrm{g}$ and gonadorelin $0.1 \mathrm{mg}$, respectively. Responses on transitioning to an upright posture could not be investigated due to the patient's refusal because of knee pain and lower limb muscle weakness. Results are shown in Figure 2. Serum cortisol levels increased only in response to 


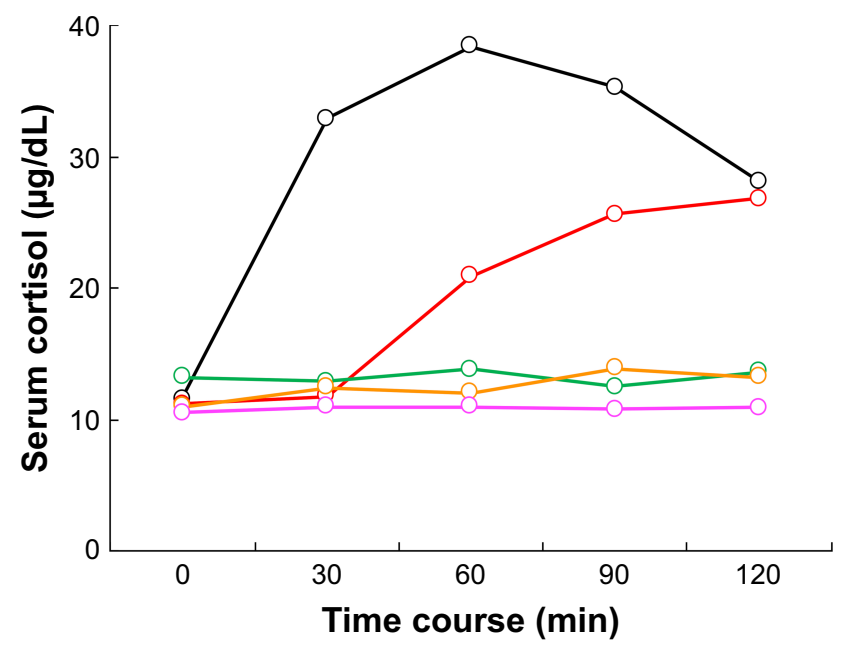

\begin{tabular}{|ll|}
\hline -O- ACTH & -- Metoclopramide \\
$-\mathrm{O}-$ Glucagon & $-\mathrm{O}-$ Mixed meal \\
$-\mathrm{-}-$ GnRH & \\
\hline
\end{tabular}

Figure 2 Aberrant responses of cortisol secretion preoperatively.

Notes: Vertical axis indicates serum cortisol level. Horizontal axis indicates time course after exogenous stimuli.

Abbreviations: ACTH, adrenocorticotropic hormone; $\mathrm{GnRH}$, gonadotropinreleasing hormone.

ACTH and metoclopramide administration. The increased cortisol level following metoclopramide administration was $239 \%$ from a baseline of 11.2 to a peak of $26.8 \mu \mathrm{g} / \mathrm{dL}$.

Based on the above data, the patient was diagnosed as having BMAH and underwent left adrenalectomy. Surgery was successful, and the dose of postoperative glucocorticoid replacement therapy was uneventfully reduced to hydrocortisone $15 \mathrm{mg} /$ day $(10 \mathrm{mg}$ after breakfast and $5 \mathrm{mg}$ after dinner) at day 6 . On the morning of postoperative day 8 , prior to use of hydrocortisone in the morning, the fasting serum cortisol response against oral metoclopramide $10 \mathrm{mg}$ was investigated once again. A baseline morning cortisol level of $2.96 \mu \mathrm{g} / \mathrm{dL}$ strongly suggested adrenal insufficiency, but the peak level following administration of metoclopramide was at $19.7 \mu \mathrm{g} / \mathrm{dL}$ (representing an increase of $666 \%$, Figure 3 ). On receiving hydrocortisone $15 \mathrm{mg} /$ day, the patient showed no signs of adrenal insufficiency thereafter, and was therefore uneventfully discharged at postoperative day 10 .

Serum cortisol levels prior to hydrocortisone in the morning were monitored on an outpatient basis on postoperative day 72 and 109, when the patient was receiving hydrocortisone $12.5 \mathrm{mg} /$ day (10 $\mathrm{mg}$ after breakfast and $2.5 \mathrm{mg}$ after dinner). Markedly decreased morning serum cortisol levels were repeatedly confirmed, and adrenal insufficiency was strongly suggested even at day 109; thus, steroid coverage could not be withdrawn (Figure 4). Undetectable ACTH

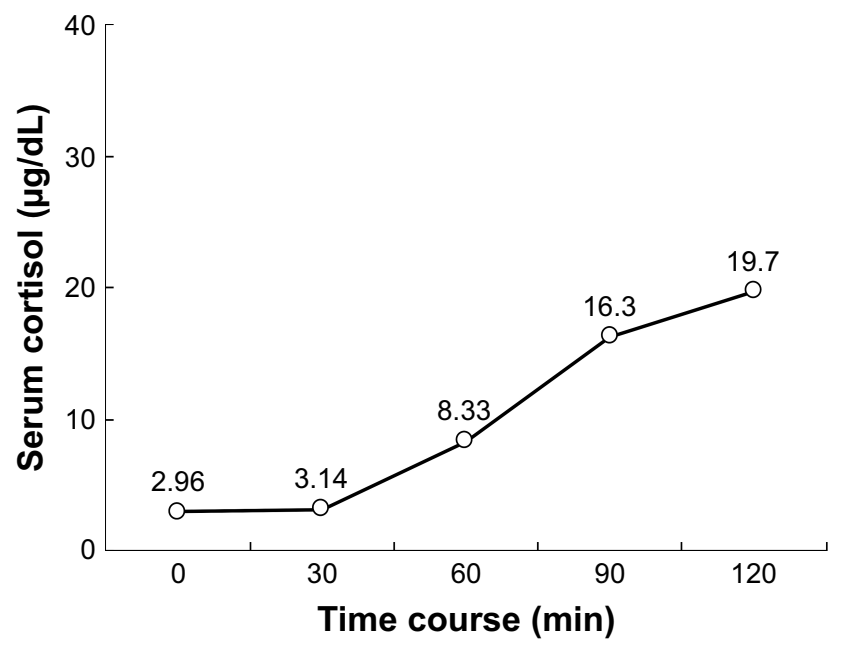

Figure 3 Cortisol secretion on metoclopramide challenge at postoperative day 8 . Notes: Vertical axis indicates serum cortisol level. Horizontal axis indicates time course after metoclopramide administration. Numerical values are also shown with trajectory.

at $<2 \mathrm{pg} / \mathrm{mL}$ was sustained throughout the observation period, which also suggested an unrestored hypothalamuspituitary-adrenal (HPA) axis. Meanwhile, the patient's weight was successfully reduced to $53.0 \mathrm{~kg}$ with a BMI of $24.5 \mathrm{~kg} / \mathrm{m}^{2}$, and hypertension is currently controlled at 120-140/70-90 mmHg with amlodipine $5 \mathrm{mg}$ /day alone.

\section{Discussion}

BMAH is a rare subtype of adrenal Cushing's syndrome, and genetic involvement is suggested because of bilateral

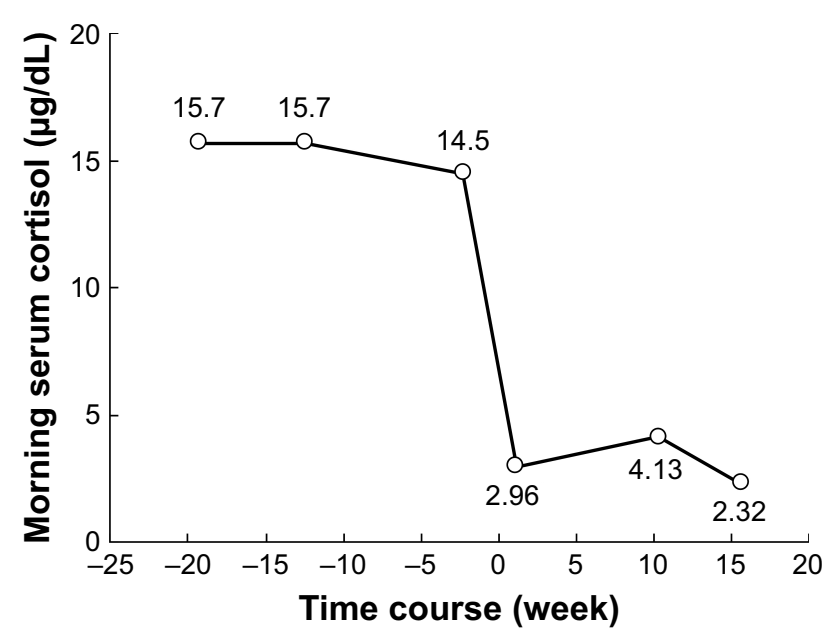

Figure 4 Time course of morning serum cortisol before and after left adrenalectomy. Notes: Vertical axis indicates morning serum cortisol level. Horizontal axis indicates time course before and after left adrenalectomy (week 0). Three data points collected before surgery, and data collected at postoperative days 8,72 and 109 are shown. Regimen of steroid coverage at day 8 was hydrocortisone $15 \mathrm{mg} /$ day ( 10 and $5 \mathrm{mg}$ after breakfast and dinner, respectively). Regimen of steroid coverage at days 72 and 109 was hydrocortisone $12.5 \mathrm{mg} /$ day, 10 and $2.5 \mathrm{mg}$ after breakfast and dinner, respectively. Numerical values are also shown with trajectory. 
involvement and reports of familial cases. A major genetic characteristic is the presence of inactivating mutations of $A R M C 5$, a potential tumor suppressor gene; biallelic alterations consisting of an additive pathogenic somatic mutation and a germline mutation inactivating ARMC5 result in nodule formation in the adrenal glands of BMAH patients. ${ }^{10} \mathrm{Clini}-$ cally, Cushing's syndrome of BMAH type is characterized by marked bilateral enlargement of the adrenal glands and aberrant cortisol secretion responses on challenge with exogenous stimuli. ${ }^{1}$ Previously, several investigators reported that this aberrant response is associated with an upright posture, eating a mixed meal, ACTH, GnRH, thyrotropin-releasing hormone, glucagon, vasopressin and serotonin type 4 receptor agonists including metoclopramide which was first described by Lacroix et al in $1999 .^{2-8}$ The present case we describe here is a patient with BMAH associated with an aberrant response of cortisol secretion on metoclopramide challenge. Clinical profiles such as age, nodule sizes and urinary cortisol excretion in the present case seem similar to the previously reported BMAH cases with aberrant responses to metoclopramide administration (Table 1). ${ }^{2,3,5,7,8}$ However, this patient highlights two clinically important issues. First, metoclopramide-stimulated aberrant cortisol secretion responses by the remaining adrenal gland are retained even under conditions of adrenal insufficiency in the early postoperative period. Second, the impact of metoclopramide use in such cases has a substantial ability to conceal adrenal insufficiency as assessed by morning, or randomly timed, serum cortisol level determinations.

In the present case, adrenal insufficiency after left adrenalectomy was apparent, and did not recover over the observation period; thus, morning serum cortisol levels were 2.96, 4.13 and $2.12 \mu \mathrm{g} / \mathrm{dL}$ on postoperative day 8,72 and 109 . This is sufficiently low to predict adrenal insufficiency because a recent retrospective cohort study reported that morning serum cortisol level was correlated with peak serum cortisol level on an insulin hypoglycemia test, with morning cortisol level below $4 \mu \mathrm{g} / \mathrm{dL}$ or above $17 \mu \mathrm{g} / \mathrm{dL}$ being highly predictive of insufficient and sufficient adrenal function, respectively. ${ }^{11}$ Furthermore, another retrospective cohort study reported an association between randomly sampled serum cortisol levels and the results of ACTH testing. In that study, a cortisol level below $5.1 \mu \mathrm{g} / \mathrm{dL}$ predicted a 30 minutes serum cortisol level below $20 \mu \mathrm{g} / \mathrm{dL}$ during the ACTH test, indicating insufficient adrenal function, with $100 \%$ specificity and $35 \%$ sensitivity. ${ }^{12}$ In contrast, a value exceeding $>15.2 \mu \mathrm{g} / \mathrm{dL}$ guaranteed a 30 minutes value exceeding $20 \mu \mathrm{g} / \mathrm{dL}$ during the ACTH test, indicating adequate adrenal function. ${ }^{12}$ Therefore, it seems highly likely that our patient had adrenal insufficiency sustained until at least postoperative day 109.

The postoperative course of adrenal function observed in this present case is not a chance event, because a previous retrospective study reported that postoperative adrenal insufficiency following unilateral adrenalectomy in BMAH patients was observed in $40 \%$ of patients ( 6 of 15 enrolled). ${ }^{13}$ The report also remarked that adrenal insufficiency and the following latent adrenal insufficiency persisted for two years or more. ${ }^{13}$ It was also mentioned that the $250 \mu \mathrm{g}$ synacthen test was unreliable for diagnosis of adrenal insufficiency in such situations because the cortisol secretory response to a challenge of $250 \mu \mathrm{g}$ synacthen could occur even under conditions of adrenal insufficiency after surgery. ${ }^{13}$ Similarly, this present case indicates that the remaining gland still did have substantial cortisol secretory capacity when stimulated via an aberrant GPCRs, even though the patient was ordinarily adrenal-insufficient.

The $666 \%$ increase in the serum cortisol level following metoclopramide stimulation observed after surgery is of interest. Although the baseline serum cortisol level of $2.96 \mu \mathrm{g} / \mathrm{dL}$ was strongly suggestive of adrenal insufficiency, the peak value of $19.7 \mu \mathrm{g} / \mathrm{dL}$ would indicate sufficient adrenal function when measured either in the morning or randomly. ${ }^{11,12}$ In the clinical setting, morning or random serum cortisol measurement is frequently used to assess HPA axis functionality because it is easy to perform. However, the marked fluctuation of serum cortisol level observed in this present case suggests that external stimuli associated with aberrant cortisol secretion can conceal underlying adrenal insufficiency and mislead clinicians assessing the HPA axis after unilateral adrenalectomy in BMAH patients. Because metoclopramide is frequently used, also after surgery, caution is required to avoid the risk of inappropriate withdrawal of steroid coverage. Moreover, habitual use of metoclopramide might suppress the hypothalamus and pituitary via negative feedback due to cortisol excess, and lead to delayed recovery of the HPA axis. Similarly, this risk should be considered in all patients with BMAH receiving unilateral adrenalectomy, because not only metoclopramide but also upright posture or eating a mixed meal, always happening in daily life, were also reported to induce cortisol secretion. ${ }^{3,7,8}$ To conclude, detailed surveillance of aberrant cortisol secretion responses on challenge with exogenous stimuli influencing aberrant GPCRs is clinically important in BMAH patients.

This report has certain limitations. First, it is an observational case report of a single patient, and there are several 
Table I Review of BMAH cases with paradoxical cortisol secretion response on metoclopramide challenge

\begin{tabular}{|c|c|c|c|c|c|c|c|c|c|c|}
\hline \multirow[t]{2}{*}{ Case } & \multirow[t]{2}{*}{ Author } & \multirow[t]{2}{*}{ Sex } & \multirow[t]{2}{*}{$\begin{array}{l}\text { Age } \\
\text { (years) }\end{array}$} & \multirow[t]{2}{*}{$\begin{array}{l}\text { BMI } \\
\left(\mathrm{kg} / \mathrm{m}^{2}\right)\end{array}$} & \multirow[t]{2}{*}{ Function } & \multirow[t]{2}{*}{ Maleifestation } & \multicolumn{2}{|c|}{$\begin{array}{l}\text { Nodule size } \\
(\mathrm{mm})\end{array}$} & \multirow[t]{2}{*}{$\begin{array}{l}\text { U-Cor } \\
(\mu g / \text { day })\end{array}$} & \multirow{2}{*}{$\begin{array}{l}\text { Degree of } \\
\text { increase } \\
(\%)\end{array}$} \\
\hline & & & & & & & Right & Left & & \\
\hline I & \multirow[t]{17}{*}{ Libé $\mathrm{R}$} & Male & 53 & 31.2 & CS & Cushing's sign & 35 & 45 & 293 & 133 \\
\hline 2 & & Female & 34 & 30.0 & CS & Cushing's sign & 45 & 30 & 373 & 180 \\
\hline 3 & & Female & 70 & 25.0 & CS & Incidentaloma & 50 & 30 & 122 & 204 \\
\hline 4 & & Female & 45 & 21.3 & SCS & Incidentaloma & 60 & 30 & 44 & 438 \\
\hline 5 & & Female & 37 & 30.5 & SCS & Incidentaloma & 33 & 15 & 26 & 185 \\
\hline 6 & & Male & 59 & 25.6 & SCS & Hypertension & 30 & 60 & 31 & 426 \\
\hline 7 & & Female & 66 & 27.8 & SCS & Incidentaloma & 14 & 30 & 29 & 209 \\
\hline 8 & & Female & 35 & 27.4 & SCS & Incidentaloma & 26 & 27 & 18 & 180 \\
\hline 9 & & Female & 67 & 28.6 & SCS & Incidentaloma & 14 & 40 & 56 & 209 \\
\hline 10 & & Female & 54 & 28.2 & SCS & Incidentaloma & 18 & 44 & 36 & 137 \\
\hline 11 & & Female & 53 & 26.7 & SCS & Incidentaloma & 35 & 27 & 83 & 310 \\
\hline 12 & & Male & 74 & 23.3 & SCS & Incidentaloma & 20 & 25 & 85 & 160 \\
\hline 13 & & Male & 51 & 20.6 & SCS & Incidentaloma & 27 & 40 & 63 & 206 \\
\hline 14 & & Male & 52 & 27.0 & SCS & Incidentaloma & 55 & 46 & 50 & 138 \\
\hline 15 & & Male & 51 & 24.0 & SCS & Incidentaloma & 40 & 37 & 47 & 183 \\
\hline 16 & & Female & 43 & 22.3 & SCS & Incidentaloma & 45 & 15 & 46 & 154 \\
\hline 17 & & Female & 55 & 33.6 & SCS & Hypertension & 30 & 24 & 26 & 183 \\
\hline 18 & \multirow[t]{3}{*}{ Bourdeau I } & Female & 51 & NA & SCS & Hypertension, weight gain & 44 & 50 & NA & 145 \\
\hline 19 & & Male & 61 & NA & SCS & & 61 & 73 & NA & 191 \\
\hline 20 & & Male & 53 & 25.3 & SCS & Hypertension & 35 & 40 & NA & 300 \\
\hline 21 & \multirow[t]{2}{*}{ Vezzosi D } & Female & 56 & NA & CS & $\begin{array}{l}\text { Hypertension, } \\
\text { centripetal obesity, facial } \\
\text { plethora, dorsal fat pad } \\
\text { supraclavicular fat pad, } \\
\text { glucose intolerance, mild } \\
\text { hirsutism }\end{array}$ & NA & NA & 34 & 270 \\
\hline 22 & & Female & 54 & NA & CS & $\begin{array}{l}\text { Hypertension, centripetal } \\
\text { obesity, facial plethora, easy } \\
\text { bruising, diabetes mellitus }\end{array}$ & NA & NA & 50 & 301 \\
\hline 23 & \multirow[t]{2}{*}{ Feelders RA } & Female & 60 & 24.4 & CS & $\begin{array}{l}\text { Centripetal obesity, facial } \\
\text { plethora, muscle weakness, } \\
\text { easy bruising depression, } \\
\text { skin atrophy }\end{array}$ & 35 & 50 & $199-228$ & 289 \\
\hline 24 & & Female & 40 & 32.8 & CS & $\begin{array}{l}\text { Hypertension, centripetal } \\
\text { obesity, facial plethora, } \\
\text { weight gain, muscle } \\
\text { weakness, easy bruising, } \\
\text { dorsal fat pad, supraclavicular } \\
\text { fat pad, depression }\end{array}$ & 50 & 30 & $326-652$ & 195 \\
\hline 25 & Lacroix A & Female & 63 & 28.9 & $\mathrm{CS}$ & $\begin{array}{l}\text { Hypertension, weight } \\
\text { gain, muscle weakness, } \\
\text { numbness, hot flushes, } \\
\text { decrease in concentration } \\
\text { and memory }\end{array}$ & 40 & 40 & 279 & 257 \\
\hline
\end{tabular}

Note: Clinical features of cases with BMAH reported to be associated with paradoxical response of cortisol secretion on metoclopramide challenge are shown together with the percentage increase of cortisol level.

Abbreviations: BMAH, bilateral macronodular adrenal hyperplasia; BMI, body mass index; CS, Cushing's syndrome; NA, not applicable; SCS, subclinical Cushing's syndrome; U-Cor, urinary cortisol excretion.

unavailable data, such as results of a vasopressin test, a postoperative synacthen test and postoperative urinary free cortisol excretion. Further cases with fully-assessed pre- and postoperative aberrant responses to exogeneous stimuli must be accumulated to assess cortisol secretory capacity after surgery in BMAH. Second, cortisol levels following metoclopramide stimulation after surgery were possibly modified by hydrocortisone use, despite the small doses applied (15 mg/day), so underestimates cannot be excluded. 


\section{Conclusion}

The aberrant cortisol secretion response after exogenous stimulation influencing aberrant G-protein-coupled receptors was found to be retained in a patient with BMAH, even in a state of adrenal insufficiency after unilateral adrenalectomy. Thus, a high serum cortisol level when the patient receives such exogenous stimuli does not guarantee efficient adrenal function. Caution is thus required for assessing the actual status of the HPA axis.

\section{Abbreviations}

ACTH, adrenocorticotropic hormone; BMAH, bilateral macronodular hyperplasia; BMI, body mass index; GnRH, gonadotropin-releasing hormone; GPCRs, G-protein-coupled receptors; HPA, hypothalamus-pituitary-adrenal.

\section{Ethics and consent for publication}

The patient described in this study provided permission to publish data and accompanying images, and written informed consent was obtained. A formal ethical review by an institutional review board was not required because this is a case report.

\section{Acknowledgment}

This report was not funded by any specific grant from funding agencies in the public, commercial, or not-for-profit sectors.

\section{Author contributions}

ST designed the study, contributed to collect, analyze and interpret data, and wrote the initial draft of the manuscript. MF contributed to interpret the data, and assisted in the preparation of the manuscript. All authors contributed to data analysis, drafting and revising the article, gave final approval of the version to be published, and agree to be accountable for all aspects of the work.

\section{Disclosure}

The authors report no conflicts of interest in this work.

\section{References}

1. El Ghorayeb N, Bourdeau I, Lacroix A. Multiple aberrant hormone receptors in Cushing's syndrome. Eur J Endocrinol. 2015;173(4): M45-M60.

2. Lacroix A, Hamet P, Boutin JM. Leuprolide acetate therapy in luteinizing hormone - dependent Cushing's syndrome. N Engl J Med. 1999; 341(21):1577-1581

3. Bourdeau I, D'Amour P, Hamet P, Boutin JM, Lacroix A. Aberrant membrane hormone receptors in incidentally discovered bilateral macronodular adrenal hyperplasia with subclinical Cushing's syndrome. J Clin Endocrinol Metab. 2001;86(11):5534-5540.

4. Cartier D, Lihrmann I, Parmentier F, et al. Overexpression of serotonin4 receptors in cisapride-responsive adrenocorticotropin-independent bilateral macronodular adrenal hyperplasia causing Cushing's syndrome. $J$ Clin Endocrinol Metab. 2003;88(1):248-254.

5. Feelders RA, Lamberts SW, Hofland LJ, et al. Luteinizing hormone (LH)-responsive Cushing's syndrome: the demonstration of LH receptor messenger ribonucleic acid in hyperplastic adrenal cells, which respond to chorionic gonadotropin and serotonin agonists in vitro. $J$ Clin Endocrinol Metab. 2003;88(1):230-237.

6. Louiset E, Contesse V, Groussin L, et al. Expression of serotonin7 receptor and coupling of ectopic receptors to protein kinase A and ionic currents in adrenocorticotropin-independent macronodular adrenal hyperplasia causing Cushing's syndrome. J Clin Endocrinol Metab. 2006;91(11):4578-4586.

7. Vezzosi D, Cartier D, Régnier C, et al. Familial adrenocorticotropinindependent macronodular adrenal hyperplasia with aberrant serotonin and vasopressin adrenal receptors. Eur J Endocrinol. 2007;156(1): 21-31.

8. Libé R, Coste J, Guignat L, et al. Aberrant cortisol regulations in bilateral macronodular adrenal hyperplasia: a frequent finding in a prospective study of 32 patients with overt or subclinical Cushing's syndrome. Eur J Endocrinol. 2010;163(1):129-138.

9. Lacroix A. ACTH-independent macronodular adrenal hyperplasia. Best Pract Res Clin Endocrinol Metab. 2009;23(2):245-259.

10. Assié G, Libé R, Espiard S, et al. Armc5 mutations in macronodular adrenal hyperplasia with Cushing's syndrome. $N$ Engl J Med. 2013; 369(22):2105-2114.

11. Erturk E, Jaffe CA, Barkan AL. Evaluation of the integrity of the hypothalamic-pituitary-adrenal axis by insulin hypoglycemia test. J Clin Endocrinol Metab. 1998;83(7):2350-2354.

12. Kadiyala R, Kamath C, Baglioni P, Geen J, Okosieme OE. Can a random serum cortisol reduce the need for short synacthen tests in acute medical admissions? Ann Clin Biochem. 2010;47(Pt 4):378-380.

13. Debillon E, Velayoudom-Cephise FL, Salenave S, et al. Unilateral adrenalectomy as a first-line treatment of Cushing's syndrome in patients with primary bilateral macronodular adrenal hyperplasia. J Clin Endocrinol Metab. 2015;100(12):4417-4424.
Therapeutics and Clinical Risk Management

\section{Publish your work in this journal}

Therapeutics and Clinical Risk Management is an international, peerreviewed journal of clinical therapeutics and risk management, focusing on concise rapid reporting of clinical studies in all therapeutic areas, outcomes, safety, and programs for the effective, safe, and sustained use of medicines. This journal is indexed on PubMed Central, CAS,

\section{Dovepress}

EMBase, Scopus and the Elsevier Bibliographic databases. The manuscript management system is completely online and includes a very quick and fair peer-review system, which is all easy to use. Visit $\mathrm{http}: / / \mathrm{www}$.dovepress.com/testimonials.php to read real quotes from published authors. 